\title{
Cardiac Beat Detected
}

National Cancer Institute

\section{Source}

National Cancer Institute. Cardiac Beat Detected. NCI Thesaurus. Code C69191.

An indication that a heart beat was detected and rejected as not conforming to the measurement standards. 